\title{
A New Method to Determine the Lower Limit of Reservoir Physical Properties-Corrected Minimum Flow Pore-throat Radius Method
}

\author{
Jinyou Dai ${ }^{1,2, *}$ Lixin Lin $^{2}$, and Rui Wang ${ }^{2}$ \\ ${ }^{1}$ State Key Laboratory of Petroleum Resources and Prospecting, China University of Petroleum Beijing, Beijing, China \\ ${ }^{2}$ School of Petroleum Engineering, China University of Petroleum Beijing, Beijing, China
}

\begin{abstract}
The lower limit of reservoir physical properties is an important parameter for identifying reservoirs and determining effective thickness in reserves evaluation, and is also an important basis for selecting perforated test intervals in oilfield exploration and development. There are many methods to determine the lower limit of reservoir physical properties, and the minimum flow pore throat radius method is one of the commonly used methods. The method uses $0.1 \mu \mathrm{m}$ as the minimum flow pore-throat radius, and uses this to calibrate the lower limit of reservoir physical properties. However, according to the water film theory, the minimum radius of the reservoir's flowing pore throat is not a definite value, but varies with the displacement dynamics. Therefore, there is no exact basis for using $0.1 \mu \mathrm{m}$ as the minimum flow pore-throat radius, so it needs to be corrected. To this end, a new method for determining the lower limit of reservoir physical properties - the corrected minimum flow pore-throat radius method is proposed. The correction method comprehensively considers the factors of oil and gas accumulation dynamics, and determines the lower limit of reservoir physical properties by obtaining the minimum flow pore-throat radius value suitable for oil and gas accumulation dynamics. A case study of Chang $6^{3}$ reservoir in A Oilfield shows that the minimum flow pore radius of oil and gas determined by the correction method is $0.08 \mu \mathrm{m}$, and the lower limit of reservoir physical properties (porosity $9.1 \%$, permeability $0.117 \times 10^{-3} \mu^{2}$ ). The traditional method has a minimum flow pore-throat radius of $0.1 \mu \mathrm{m}$ and a lower limit of reservoir physical properties (porosity of $9.8 \%$ and permeability of $0.133 \times 10^{-3} \mu \mathrm{m}^{2}$ ). Due to full consideration of the impact of oil and gas accumulation dynamics, the minimum flow pore-throat radius determined by the correction method is more reliable than the traditional method, and the lower limit of the reservoir physical property calibrated by it has practical significance.
\end{abstract}

\section{Introduction}

The lower limit of reservoir physical properties is the minimum effective porosity and minimum permeability that can store and percolate fluid. It is usually expressed by a certain value of porosity or permeability ${ }^{[1]}$. The lower limit of reservoir physical properties is an important parameter for identifying reservoirs and determining effective thickness in reserves evaluation, and it is also an important basis for selecting perforated test intervals in oilfield exploration and development ${ }^{[2-3]}$. In view of the basicity and necessity of the lower limit of reservoir physical properties, research on the lower limit of reservoir physical properties is the focus of oil and gas reservoir geology and engineering. For a long time, many scientists and technicians have conducted a lot of research on the lower limit of reservoir physical properties, and put forward more methods to determine the lower limit of reservoir physical properties ${ }^{[4-31]}$. Among them, the minimum flow pore-throat radius method is one of the commonly used methods to determine the lower limit of reservoir physical properties [24-31]. The method believes that the pores and throats of rocks are spaces and channels for oil and gas storage and flow. Whether oil and gas can flow out of rocks under a certain pressure difference depends on the thickness of the throat. That is, the radius of the rock throat is the key factor that determines whether oil and gas can flow out of the rock under a certain pressure difference. This minimum throat radius that can store oil and gas and allow oil and gas to seep is the minimum flow porethroat radius of oil and gas ${ }^{[24,25,32]}$. After determining the minimum flow pore-throat radius, the correlation curve of pore-throat radius and porosity and permeability can be drawn according to the principle of statistical analysis, and the corresponding porosity and permeability lower limit values can be calibrated according to the minimum flow pore-throat radius ${ }^{[26-27]}$. At present, the minimum flow pore-throat radius method generally adopts $0.1 \mu \mathrm{m}$ as the minimum flow pore-throat radius of oil and gas. It is also believed that $0.1 \mu \mathrm{m}$ is equivalent to the thickness

*Corresponding author e-mail: d772512281@qq.com 
of the water film attached to the surface of the water-wet clastic rock. The pore-throat radius is less than this value. Oil and gas are not flowing, and the corresponding porosity and permeability values are the lower limits of reservoir physical properties ${ }^{[24-31]}$.

The advantage of the minimum flow pore-throat radius method is that the lower limit of the reservoir physical properties and the minimum flow pore-throat radius are linked together, and the lower limit of the reservoir physical properties corresponding to the specific pore-throat radius $(0.1 \mu \mathrm{m})$ is calibrated. The process is simple and clear, easy to master. However, this method also has obvious shortcomings. The theoretical basis for determining the minimum flow porethroat radius as a fixed value $(0.1 \mu \mathrm{m})$ is not sufficient. According to previous studies on water film theory ${ }^{[33-34]}$, the thickness of the water film attached to the rock surface is not fixed, and the thickness of the water film is a function of the displacement pressure. As the displacement power increases, the thickness of the water film gradually decreases, and the corresponding minimum flow pore-throat radius of oil and gas must also decrease, which shows that the minimum flow porethroat radius should not be a certain value. From this point of view, it is not appropriate to use $0.1 \mu \mathrm{m}$ as the minimum flow pore-throat radius, and there is a certain deviation in the lower limit of the physical properties calibrated by this. Therefore, how to calculate the minimum flow pore-throat radius value more accurately? It is the key to objectively calibrate the lower limit of reservoir physical properties using the minimum flow pore-throat radius method. To this end, this paper proposes a new method to determine the lower limit of reservoir physical properties-the corrected minimum flow pore-throat radius method (hereinafter referred to as the correction method).

\section{Method principle}

Pore throats in reservoirs vary in size and geometry, and pore throats of different orders interweave to form an intricately interconnected system. The complexity of the reservoir pore-throat network, especially the order of pore-throat distribution, will inevitably have a direct and significant effect on the seepage response of the reservoir fluid. When the displacement power is constant, only the part of the pore-throat network with pore-throat size greater than a certain limit will seep, while other parts of the pore-throat network below this limit cannot seep. That is, the fluid seepage in the pore-throat network is selective. This phenomenon can be understood as, as the pore-throat size of the reservoir decreases, the liquid particles are continuously strengthened by the capillary force and the molecular force of the surrounding solid interface, and the seepage resistance increases accordingly. When the pore-throat radius reaches a certain limit, the displacement power and the seepage resistance are in equilibrium. When the pore-throat radius is greater than this limit, the displacement power is greater than the seepage resistance, and the liquid flows. When the pore-throat radius is smaller than this limit, the displacement power is less than the seepage resistance, and the liquid does not flow. Therefore, the pore-throat radius in the displacement equilibrium state is the minimum flow pore-throat radius.

As the displacement power increases, the minimum flow pore-throat radius of the reservoir gradually decreases. When the minimum flow pore-throat radius of the reservoir is reduced to just the full use of oil and gas in the reservoir, the corresponding minimum flow porethroat radius is the minimum flow pore-throat radius of the oil and gas, and the lower limit of physical properties calibrated based on this is the effective lower limit. Because the production process is limited by many factors, it is difficult to accurately determine whether the oil and gas are fully utilized and the minimum flow porethroat radius when the oil and gas is fully utilized. However, considering that the process of oil and gas accumulation and production is the reciprocal process of oil drainage and water flooding, the minimum flow porethroat radius of oil and gas can be obtained according to the oil and gas accumulation dynamics.

The mercury intrusion curve is a curve reflecting the change of the saturation of the non-wet phase with the displacement pressure during the displacement of the wet-phase fluid by the non-wet phase fluid. The mercury intrusion process can be regarded as the accumulation and filling process of oil drainage, so the mercury intrusion curve actually reflects the correspondence between oil saturation and accumulation dynamics. In other words, the mercury inlet pressure corresponding to the original oil saturation read on the mercury pressure curve is the accumulation power, and the pore-throat radius corresponding to this accumulation power is the minimum pore-throat radius of oil and gas. Based on the determination of the minimum flow pore-throat radius, and then based on the principle of statistical analysis, the correlation curve of pore-throat radius and porosity and permeability is drawn, and the lower limit of reservoir physical properties can be calibrated according to the minimum flow pore-throat radius. Taking the Chang $6_{3}$ reservoir in the A oilfield of the Ordos Basin as an example, the lower limit of the physical properties of the reservoir is determined by the correction method.

\section{Calculation example}

\subsection{Geological overview}

The structure of the A oil field belongs to the southwest of the Yishan slope in the Ordos Basin. It is located in Huachi and Qingyang in Gansu Province, with an area of $2600 \mathrm{~km}^{2}$. More than 300 exploration and evaluation wells have been drilled. The main production layer of the oil field is the Chang 63 oil group of the Upper Triassic Yanchang Formation in the Triassic system, which belongs to the gravity flow sedimentation of deep lakesemi-deep lake facies, with an average thickness of $47 \mathrm{~m}$ and a sand-to-land ratio of 0.52 . The surface of the area belongs to the loess plateau landform, the terrain is undulating, the ground elevation is about $1150-1650 \mathrm{~m}$, and the relative height difference is about $500 \mathrm{~m}$. The 
structure of Chang 6 period is relatively simple. The overall structure is a gentle west-dipping monoclinic with an inclination angle of less than 1 degree. Analysis of core physical property data of 8288 samples from 77 cored wells shows that the porosity of Chang $6_{3}$ reservoir in A oilfield is distributed between 4 and $15 \%$, with an average porosity of $9.1 \%$. The permeability distribution is between 0.01 and $0.8 \times 10^{-3} \mu^{2}$, and the average permeability is $0.152 \times 10^{-3} \mu \mathrm{m}^{2}$. The reservoir belongs to ultra-low porosity-ultra-low permeability reservoir.

\subsection{Characteristics of mercury intrusion curve}

Based on core observation and sample collection, five rock samples were selected for mercury intrusion experiment. The characteristics of the rock samples are shown in Table 1. It can be seen that the porosity of the rock samples is distributed between 6.86 and 13.51\%, with an average of $9.97 \%$; the permeability is distributed between 0.035 and $0.203 \times 10^{-3} \mu \mathrm{m}^{2}$, with an average of $0.137 \times 10^{-3} \mu \mathrm{m}^{2}$; It can reflect the physical properties of Chang $6_{3}$ low porosity and low permeability reservoir.

Table 1. Characteristics of rock samples.

\begin{tabular}{cccccccc}
\hline Well no. & $\begin{array}{c}\text { Well } \\
\text { depth }(\mathrm{m})\end{array}$ & horizon & $\begin{array}{c}\text { Core } \\
\text { number }\end{array}$ & $\begin{array}{c}\text { Length } \\
(\mathrm{cm})\end{array}$ & $\begin{array}{c}\text { Diameter } \\
(\mathrm{cm})\end{array}$ & $\begin{array}{c}\text { Porosity } \\
(\%)\end{array}$ & $\begin{array}{c}\text { Permeability } \\
\left(\times 10^{-3} \mathrm{~mm}^{2}\right)\end{array}$ \\
\hline Shan 127 & 1951.25 & Chang 63 & $1 \#$ & 6.45 & 2.53 & 12.06 & 0.203 \\
Bai 221 & 2064.1 & Chang 63 & $2 \#$ & 6.46 & 2.53 & 13.51 & 0.186 \\
Bai 269 & 1936.27 & Chang 63 & $3 \#$ & 6.1 & 2.53 & 9.21 & 0.123 \\
Shan 156 & 2060.1 & Chang 63 & $4 \#$ & 6.41 & 2.53 & 8.23 & 0.137 \\
Wu 85 & 1991.79 & Chang 63 & $5 \#$ & 6.67 & 2.53 & 6.86 & 0.035 \\
Average & & & & 6.42 & 2.53 & 9.97 & 0.137 \\
\hline
\end{tabular}

According to the experimental data of mercury intrusion, a mercury intrusion curve (Figure 1) was drawn and the characteristics of mercury intrusion parameters of rock samples were calculated (Table 2).

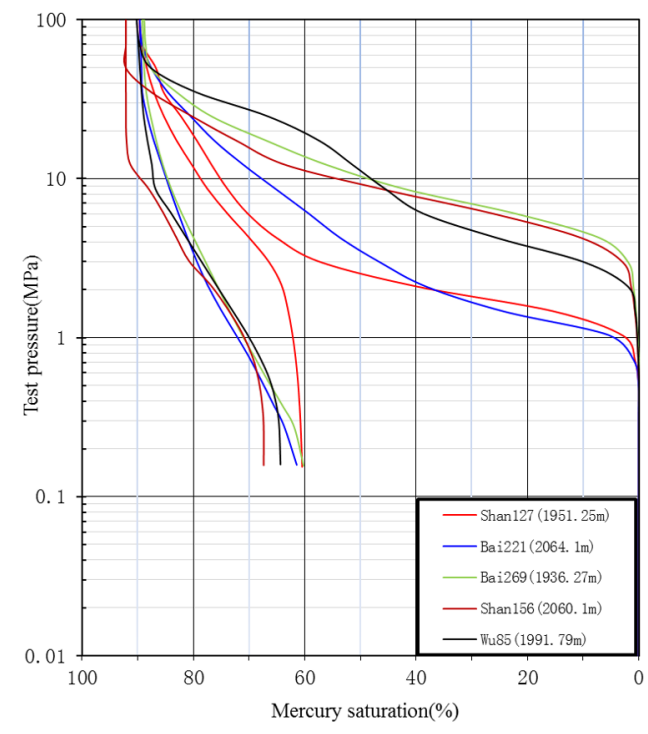

It can be seen that the displacement pressure of the five rock samples is distributed between 0.78 and $2.85 \mathrm{MPa}$, with an average of $1.82 \mathrm{MPa}$. The median pressure is distributed between 2.61 and $14.31 \mathrm{MPa}$, with an average of $8.51 \mathrm{MPa}$. The maximum pore-throat radius is distributed between 0.258 and $0.943 \mu \mathrm{m}$, with an average of $0.524 \mu \mathrm{m}$. The median throat radius is between 0.051 and $0.282 \mu \mathrm{m}$, with an average of $0.135 \mu \mathrm{m}$. The maximum mercury saturation is between 83.94 and $92.13 \%$, with an average of $87.58 \%$. The mercury withdrawal efficiency is distributed between 26.83 and $32.6 \%$, with an average of $30.36 \%$. Overall, the displacement pressure and median pressure of the Chang 63 reservoir are higher, the median throat radius is lower (average $0.135 \mu \mathrm{m}$ ), the reservoir throat is small, the maximum mercury saturation is high (average $87.58 \%$ ), and mercury is withdrawn Low efficiency (average $30.36 \%$ ).

Figure 1. Mercury injection curve of chang 63 reservoir.

\begin{tabular}{cccccccc}
\multicolumn{7}{c}{ Table 2. Characteristics of mercury injection parameters of rock samples. } \\
\hline Well no. & $\begin{array}{c}\text { Core } \\
\text { number }\end{array}$ & $\begin{array}{c}\text { Displacement } \\
\text { pressure } \\
(\mathrm{MPa})\end{array}$ & $\begin{array}{c}\text { Median } \\
\text { pressure } \\
(\mathrm{MPa})\end{array}$ & $\begin{array}{c}\text { Maximum pore- } \\
\text { throat radius } \\
(\mu \mathrm{m})\end{array}$ & $\begin{array}{c}\text { Median radius } \\
\text { of pore throat } \\
(\mu \mathrm{m})\end{array}$ & $\begin{array}{c}\text { Maximum } \\
\text { mercury saturation } \\
(\%)\end{array}$ & $\begin{array}{c}\text { Exit } \\
\text { efficiency } \\
(\%)\end{array}$ \\
\hline Shan 127 & $1 \#$ & 0.98 & 2.61 & 0.750 & 0.282 & 86.67 & 32.60 \\
Bai 221 & $2 \#$ & 0.78 & 3.60 & 0.943 & 0.204 & 87.47 & 31.50 \\
Bai 269 & $3 \#$ & 2.85 & 12.63 & 0.258 & 0.058 & 87.67 & 32.19 \\
Shan 156 & $4 \#$ & 2.55 & 9.38 & 0.288 & 0.078 & 92.13 & 26.83 \\
Wu 85 & $5 \#$ & 1.93 & 14.31 & 0.381 & 0.051 & 83.94 & 28.66 \\
Average & & 1.82 & 8.51 & 0.524 & 0.135 & 87.58 & 30.36 \\
\hline
\end{tabular}

\subsection{Reservoir-forming power and minimum flow pore-throat radius}

The original oil saturation is an important basis for determining the accumulation power. Since the rock samples taken are not in the original state, the original oil saturation cannot be measured. To this end, based on the logging interpretation results, the original oil saturation of the five rock samples is counted, and then combined with the mercury intrusion test curve to obtain the 
accumulation power and the minimum flow pore-throat radius (Table 3). It can be seen from Table 3 that the oil saturation of the five rock samples is distributed between 44.3 and $74.4 \%$, with an average of $56.1 \%$. The accumulation power is distributed between 8.97 and $9.31 \mathrm{MPa}$, with an average of $9.18 \mathrm{MPa}$. This shows that although the mercury intrusion curves of different rock samples are different in shape (Figure 1) and the oil saturations are also very different, the accumulation power is relatively stable (all around $9 \mathrm{MPa}$ ). If factors

Table 3. Characteristic table for determining the minimum flow pore-throat radius of rock samples.

\begin{tabular}{ccccc}
\hline Well no. & $\begin{array}{c}\text { Core } \\
\text { number }\end{array}$ & $\begin{array}{c}\text { Original oil saturation } \\
(\%)\end{array}$ & $\begin{array}{c}\text { Reservoir-foming } \\
\text { pressure }(\mathrm{MPa})\end{array}$ & $\begin{array}{c}\text { Minimum flow pore-throat } \\
\text { radius }(\mu \mathrm{m})\end{array}$ \\
\hline Shan 127 & $1 \#$ & 74.4 & 9.31 & \\
Bai 221 & $2 \#$ & 66.1 & 9.19 \\
Bai 269 & $3 \#$ & 44.3 & 9.17 \\
Shan 156 & $4 \#$ & 49.4 & 9.26 \\
Wu 85 & $5 \#$ & 46.2 & 8.97 & \\
Average & & 56.1 & 9.18 & 0.08 \\
\hline
\end{tabular}

\section{4 lower limit of reservoir physical properties}

On the basis of the determination of the minimum flow pore-throat radius of oil and gas in Chang $6_{3}$ oil layer, according to the principle of statistical analysis, the correlation curves of pore-throat radius and porosity and permeability are drawn (Figure 2-Figure 3). According to the minimum flow pore-throat radius, the corresponding lower limit of porosity and permeability is calculated. Figure 2 is a graph of the intersection of the median radius and porosity of the reservoir pore throats of five mercury-injected samples. It can be seen that the two are logarithmically related and the fitting relationship is as following,

$$
\mathrm{POR}=3.219 \times \ln \left(\mathrm{R}_{50}\right)+17.19
$$

The correlation coefficient is: $\mathrm{R}^{2}=0.810$.

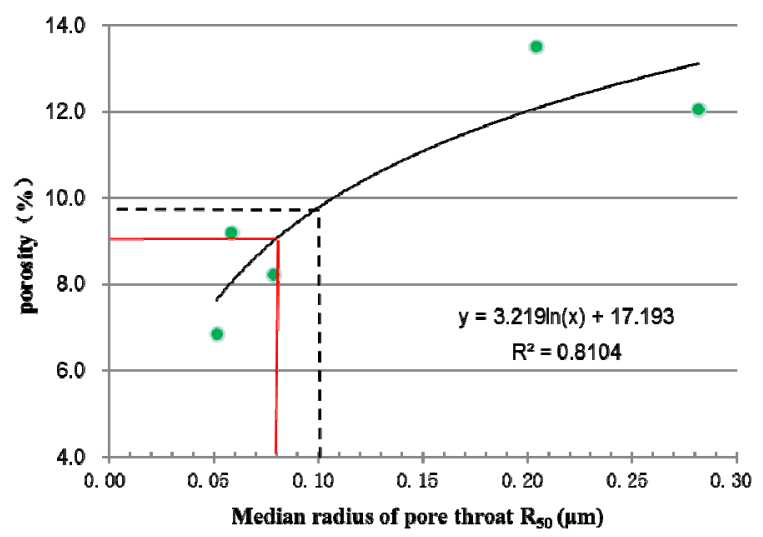

Figure 2. Crossplot of median radius of pore throat and porosity in chang 63 reservoir.

Figure 3 is the intersection graph of the median porethroat radius and permeability of five mercury-injected samples. It can be seen that the two are logarithmically related, and the fitting relationship is as following,

$$
\text { PERM }=0.075 \times \ln \left(R_{50}\right)+0.306
$$

The correlation coefficient is: $\mathrm{R}^{2}=0.781$. such as thin Chang $6_{3}$ reservoir, gentle underground structure, and interpretation error of oil saturation logging are considered, the reservoir-forming power of Chang $6_{3}$ reservoir in A oilfield is a certain value. For this reason, based on various reservoir-forming dynamics values, the reservoir-forming power of Chang $6_{3}$ reservoir calculated by arithmetic average method is 9.18 $\mathrm{MPa}$, and the corresponding minimum flow pore radius is $0.08 \mu \mathrm{m}$. 
of the reservoir physical property calibrated by it is of guiding significance.

\section{Conclusion and understanding}

The minimum flow pore-throat radius of reservoir oil and gas is not a definite value, but a function of reservoir-forming power. As the reservoir-forming power increases, the minimum flow pore-throat radius of oil and gas decreases. The traditional method of using $0.1 \mu \mathrm{m}$ as the minimum flow pore-throat radius of oil and gas lacks a precise theoretical basis and needs to be corrected. The mercury intrusion curve reflects the accumulation process of oil drainage and the corresponding relationship between oil saturation and accumulation dynamics. The mercury intrusion curve can be used to determine the reservoir accumulation dynamics and the minimum flow pore-throat radius.

The mercury intrusion test and logging interpretation oil saturation analysis of 5 samples of Chang $6_{3}$ reservoir in A oilfield show that the reservoir forming power of Chang $6_{3}$ reservoir is $9.18 \mathrm{MPa}$, the corresponding minimum flow pore radius of oil and gas is $0.08 \mu \mathrm{m}$, and the lower limit of the reservoir physical properties is: porosity $9.1 \%$, permeability $0.117 \times 10^{-3} \mu \mathrm{m}^{2}$. While the traditional method takes the minimum flow pore-throat radius of $0.1 \mu \mathrm{m}$, the lower limit of the calibration reservoir physical properties is: porosity $9.8 \%$, permeability $0.133 \times 10^{-3} \mu \mathrm{m}^{2}$. Because the influence of reservoir forming dynamics is fully considered, the minimum flow pore-throat radius determined by the correction method is more reliable than the traditional method, and the lower limit of reservoir physical properties calibrated by this method has practical significance.

\section{Acknowledgments}

This work was financially supported by the National Science and Technology Major Project "Effective Development Technology for Extra Low Permeability Reservoirs" of China (Grants No. 2011ZX05013－006).

\section{References}

1. Guo, R. (2004) Supplement to determining method of cut-off value of net pay. Petroleum Exploration and Development, 31: 140-143.

2. Liu, M.L., Feng, Z.P., Cai, Y.L., et al. (2014) Present situation and developmental trend of the research on methodology for determination of physical properties cut-off of an effective reservoir. Acta Geologica Sichuan, 34: 9-13.

3. Lu, Z.Y., Han, X.H., Zhang, X., et al. (2016) Research status and outlook for methods of determining petrophysical property cutoffs. Journal of China University of Petroleum(Edition of Natural Science), 40: 32-40.
4. Cong, L., Ma, S.Z., Li, W.L., et al. (2013) Study on physical property lower limit of effective reservoir of deep layer in Qingshui-Yuanyang Area. Advanced Materials Research, 2117: 104-108.

5. Zhang, C., Jiang, Y.Q., Guo, H.G., et al. (2010) Methods to determine the matrix petrophysical property low limits of the effective reservoir. Petroleum Geophysics, 8: 11-16.

6. Zhang, X.G. (2012) Application of empirical statistical method in the determination of lower limit of physical properties. World Well Logging Technology, 191: 17-18.

7. Geng, L.X., Cao, Y.S., Yi, Z.W., et al. (1999) A study on petrophysical property cutoffs of sandstone reservoirs in Pucheng oil field. Petroleum Exploration and Development, 26: 81-83.

8. Dong, L.Q. (2005) A research on reservoir physical texture lower-bound of the second zone of Xujiahe Formation of south area of west Sichuan, MS dissertation, Chengdu University of Technology, (April 2005).

9. Wan, N.M., Cao, Y.C., Zheng, L.J., et al. (2012) Lower limit studies of the physical properties for the effective reservoirs in sha no. 4 member of Binnanlijin area. Petroleum Geology \& Oilfield Development in Daqing, 30: 50-56.

10. Wang, Y.Z., Cao, Y.C. (2010) Lower property limit and controls on deep effective clastic reservoirs of paleogene in Chezhen depression. Acta Sedimentologica Sinica, 28: 752-761.

11. Yu, W.Q., Ye, S.D., Lu, M.J. (2011) Study on lower limit of physical properties of $\mathrm{E}_{1} \mathrm{f}_{3}$ effective reservoir in Gaoyou Sag. Complex Hydrocarbon Reservoirs, 4: 5-9.

12. Jiao, C.H., Xia, D.D., Wang, J., et al. (2009) Methods for determining the petrophysical property cutoffs of extra-low porosity and permeability sandstone reservoirs-an example from the Xishanyao Formation reservoirs in Yongjin oilfield. Oil \& Gas Geology, 30: 379-383.

13. Li, J., Yang, Y., Wang, S.F., et al. (2012) Determination of the lower limits of the physical properties of consolidated sandstone reservoirs in eastern Sulige gas field. Special Oil \& Gas Reservoirs, 18: 52-56.

14. Jin, Y.Q., Wang, G.C., Zhang, T. (2010) A new study on the lower limit standard of effective reservoir thickness in Maliangou area of Zhiluo oilfield. Science and technology of western China, 9: 11-13.

15. Cui, Y.B. (2007) Method for determining the lower limit value of effective reservoir physical properties. World Well Logging Technology, 22: 32-35.

16. Li, X.Y., Guo, J.X., Zhang, Q.X., et al. (2008) Determining method for the lower limit of physicalproperty parameters in gas reservoirs. Natural Gas Exploration and Development, 31: 33-38. 
17. Li, J., Zhao, F., Liu, P. (2012) Determination of lower limits of porosity and permeability of tight sand gas reservoirs in the eastern block of the Sulige Gas Field. Natural Gas Industry, 32: 31-35.

18. Han, X.H., Cui, Y.F., Li, F.B., et al. (2012) Classification and conventional logging identification of inhomogeneous reservoir in DB gas field. Progress in Geophysics, 27: 186-192.

19. Wang, Y.Z., Cao, Y.C., Song, G.Q., et al. (2008) Application of production test data to evaluation of the effective reservoir in deep clastic of Bonan Sag. Acta Petrolei Sinica, 29: 701-706, 710.

20. Wu, X.H., He, L., Fang, H.C. (2007) Analysis and application of specific productivity index. Petroleum Exploration and Development, 34: 745749.

21. Shao, C.X., Wang, Y.Z., Cao, Y.C. (2008) Two new methods used to determine the low limits of effective reservoir physical properties and their applications - a case study on deep clastic reservoir of Palaeogene in Dongying depression. Journal of Oil and Gas Technology, 30: 414-416.

22. Wang, Y.Z., Cao, Y.C., Song, G.Q., et al. (2009) Determination of physical property lower limit of deep clastic effective reservoirs of Paleogene in Dongying depression. Journal of China University of Petroleum(Edition of Natural Science), 33: 16-21.

23. Li, M., Liu, J.Z., Wang, X.L., et al. (2010) Study on the lower limit standard of physical properties of Chang 6 ultra-low permeability reservoir in W South area of $\mathrm{S}$ oil field. Liaoning Chemical Industry, 39: 1065-1068.

24. Peng, B., Lv, G.X. (2008) Method for determining lower limit of physical properties of low porosity and low permeability sandstone reservoirs in Shan 23 member of Zizhou gas field. Petroleum Geophysics, 6: 11-13.

25. Gao, Y., Jiang, Y.Q., Yang, C.C., et al. (2011) Minimum flow pore throat radius for determination of the lower limits of parameters in low permeability reservoir. Science \& Technology Review, 29: 34-38.

26. Wei, X.W., Xie, J.R., Tang, D.H., et al. (2008) Methods of determining the matrix petrophysical cutoffs of low porosity and low permeability sandstone reservoir - taking the $\mathrm{J}_{2} \mathrm{~s} 1$ oil reservoir in
LA field in central Sichuan as an example. Natural Gas Industry, s1: 28-31.

27. Jiang, Y.Q., Gao, Y., Xu, H.W., et al. (2010) New method for determining cut-off parameter in hydrophilic and low permeable sandstone reservoir-case of gas reservoir. Petroleum Geology and Recovery Efficiency, 17: 58-60.

28. Fu, J.H., Luo, A.X., Zhang, N.N., et al. (2014) Determine lower limits of physical properties of effective reservoirs in Chang 7 Oil Formation in Ordos Basin. China Petroleum Exploration, 19: 8287.

29. Shi, Y., Yang, Z.M., Huang, Y.Z. (2009) The study of cut-off pore-throat in reservoir. Journal of Southwest Petroleum University(Science \& Technology Edition), 31: 42-44.

30. Duan, X.G., Wang, H.H., Hu, Y.Z., et al. (2003) Methods of determining the lower limits of different parameters of reservoir in Anpeng oilfield, Henan. Journal of Chengdu University of Technology(Science \& Technology Edition), 30: 169-173.

31. Wang, W.M., Lu, S.F., Tian, W.C., et al. (2016) A new method to determine porosity and permeability cutoffs of tight oil reservoirs by using thickness of adsorption water film:A case study from the Damintun Sag,Liaohe oifield. Oil \& Gas Geology, 37: 135-140.

32. Xiang, J.H., Yin, D.Y. (2018) The lower limit of the flowing pore throat radius in the extra-low permeability reservoir. IOP Conference Series: Earth and Environmental Science, 113.

33. He, C.Z., Hua, M.Q. (1998) Thickness of water film in oil and gas reservoirs. Petroleum Exploration and Development, 25: 91-93.

34. Liu, D.X., Yue, X.A., Hou, J.R., et al. (2005) Experimental study of adsorded water layer on solid particle surface. Acta Mineralogica Sinica, 25: 1519. 